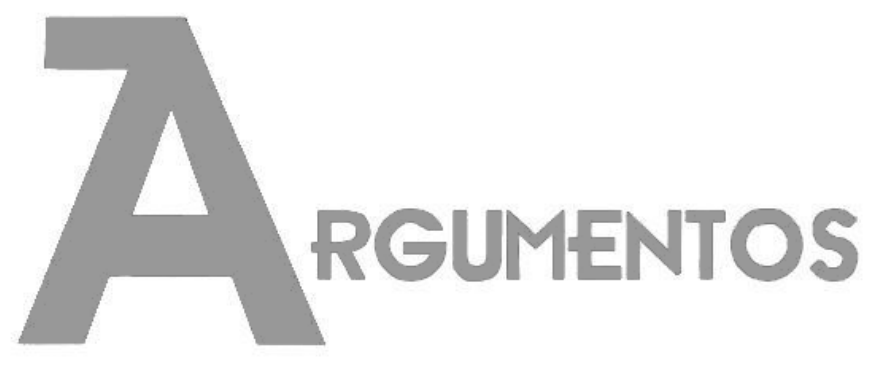

Vol. 16, n. 2, jul./dez. 2019 ISSN: 2527-2551 (online)

http://www.periodicos.unimontes.br/argumentos

\title{
Perspectivas de um pensador marginal: Octávio Brandão
}

\author{
Maria Stella D'Agostini ${ }^{1}$
}

Recebido em: 02/07/2019

Aprovado em: 26/08/2019

\begin{abstract}
Resumo: A construção de novas interpretações sobre o Brasil envolve os olhares que outrora personagens da história brasileira destinaram ao entendimento da nação. Pensadores oriundos da práxis política ou das pesquisas de gabinetes, ao longo do desenvolvimento das ciências humanas, em especial a ciência política, foram absorvidos pelas gerações posteriores em diversos níveis. Este artigo, propõe discutir a relevância do pensamento político de uma das figuras marginalizadas pelas ciências sociais hoje, Octávio Brandão. $O$ autor escolhido é um dos personagens precursores na história do marxismo nacional, cuja importância e contribuições para o pensamento político brasileiro está atrelada ao logos de seus trabalhos, como o livro Agrarismo e Industrialismo - Ensaio marxista-leninista sobre a revolta de São Paulo e a guerra de classes do Brasil, escrito em 1924, e a práxis de militante anarquista à membro fundador/dirigente do Partido Comunista Brasileiro (PCB). Conhecendo o papel de intérprete de Brandão, se pretende mostrar a originalidade, seja na incorporação do marxismo no país, seja nas táticas e estratégias elaboradas por ele e Astrojildo Pereira nas ações do Partido Comunista; tal como os desdobramentos de tais decisões no cenário nacional e histórico da agremiação e do Brasil.
\end{abstract}

Palavras-chave: Pensamento Político Brasileiro; Octávio Brandão; marxismo no Brasil; Partido Comunista Brasileiro (PCB).

\section{Perspectivas de un pensador marginado: Octávio Brandão}

Resumen: La construcción de nuevas interpretaciones sobre el Brasil involucra las miradas que alguna vez las personas de la historia brasileña tenían que buscan comprender a la nación. Los pensadores de la praxis política o de la investigación del gabinete a lo largo del desarrollo de las humanidades, especialmente en la ciencia política, fueron absorbidos por las generaciones posteriores en varios niveles. Este artículo propone discutir la relevancia del pensamiento político de una de las figuras, hoy marginadas, por las ciencias sociales, Octávio Brandão. El autor elegido es uno de los precursores en la historia del marxismo nacional cuya importancia y

\footnotetext{
${ }^{1}$ Doutoranda do Programa de Pós-graduação em Ciência Política da Universidade de Brasília (UnB), Brasil. E-mail: stellamsd@gmail.com. ORCID: https://orcid.org/0000-0002-4860-7210.
} 
contribución al pensamiento político brasileño está vinculada al logos de sus obras, como el libro "Agrarismo y Industrialismo - ensayo marxista-leninista sobre la revuelta de São Paulo y la La guerra de clases de Brasil", escrita en 1924, en Argentina, y la praxis del militante anarquista, también miembro fundador/líder del Partido Comunista Brasileño (PCB). Conociendo el papel de la interpretación de Brandão, pretendemos mostrar la originalidad, ya sea en la incorporación del marxismo en el país, o en las tácticas y estrategias elaboradas por él y Astrojildo Pereira en las acciones del Partido Comunista; como las consecuencias de tales decisiones en el escenario nacional e histórico de la asociación y Brasil.

Palabras-clave: Pensamiento político brasileño; Octavio Brandão; Marxismo en Brasil; Partido Comunista Brasileño (PCB).

\section{Perspectives of a marginal thinker: Octávio Brandão}

Abstract: The new interpretation of Brazil, constructed by our thinkers, involve different kinds of perspective about the Brazilian history, and the mode that employed their acquaintance of the nation. Thinkers who enforce a práxis and logos of political actions, during the development of our human science, specially the political science, was absorbed in various levels of understanding. This article proposes to discuss the relevance of Octávio Brandão political thought. He is one of the most underground thinkers, who had a political relevance, featured in the foundation of Brazilian's Communist Party. Also, the first intellectual using the Marxism as a method of historical analysis, putting the Brazilian political thought in a logos prism, specially in his book Agrarian and Industrial - Marxist-Leninist essay about the revolt of São Paulo and the Brazilian class struggle, wrote in 1924. The praxis prism of this thinker as from an anarchist to one of socialist leader in the Party.

Keywords: Brazilian Political Thought; Octávio Brandão; marxism in Brazil; Brazilian's Communist Party (PCB).

\section{Introdução}

Vivi no meio de perseguições sistemáticas, da indiferença ou hostilidade dos intelectuais "célebres" e do ódio das classes dominantes. ${ }^{2}$

Apesar do extenso debate sobre a originalidade do que é produzido no país, os intérpretes nacionais representam o empenho do desenvolvimento do pensamento nacional, cada um ao seu modo. Em meio a tantos olhares e teses o interlocutor assume um papel crucial para a compreensão dos argumentos defendidos. É, portanto, no cotidiano das análises da diversidade de pontos de vista sobre os fatos corriqueiros da formação, atuação e estruturação das instituições políticas brasileiras, ao longo dos anos, que se constitui o variado escopo de entendimentos nacionais organizados por Gildo Marçal Brandão (2005) como as linhagens do pensamento político brasileiro.

Se hoje existem visões e sensos comuns disseminados no país, seja sobre a formação do Estado brasileiro, seja sobre as perspectivas de atuação, como a questão

\footnotetext{
${ }^{2}$ (BRANDÃO, 1978, p. 99)
} 
do autoritarismo, do papel dos partidos políticos e da democracia racial, o debate pode ser encontrado nas teses defendidas por pensadores brasileiros de outros momentos históricos, no desenrolar da formação nacional, seguindo modas e tendências de suas épocas.

Diante da lucidez do significado geral que cada documento (escrito, oral ou gráfico) produzido por aqueles que se dispuseram pensar o país, discorrendo sobre perspectivas do passado, presente e futuro do Brasil, em seus diversos aspectos, que o papel do pensamento político, como metodologia de pesquisa, é válido e necessário no processo de construir e reconstruir o caminho das análises em diálogo com uma perspectiva contemporânea. Pensar o pensamento é, portanto, dialogar áreas afins como história dos acontecimentos, das ideias e dos intelectuais, com a construção de interpretações ao longo do tempo como as ciências sociais, filosofia política, filosofia da moral e teoria da história. Com isso ao utilizar um recorte político e social na análise, estabelecendo as conexões diacrônicas e sincrônicas, entre o pensamento do autor, o momento da história, o paradigma político e os desdobramentos dessa interlocução. Significa dizer que tanto em relação às leituras contemporâneas (diacrônicas), quanto àquelas feitas no período histórico de escrita do texto (sincrônicas) são importantes. Como descreve Brandão (2005), pensar o pensamento político brasileiro é um exercício de constante ir e vir, um caminhar longo entre texto, autor e contexto, entrelaçado por idas e vindas capazes de aproximá-lo com outros pensadores de seu período contemporâneo, alguns mais antigos que aparentemente não possuem sem qualquer similaridade; para, a partir daí, traçar o que ele chama de linhagens do pensamento político. Famílias de pensamento construídas a partir de afinidades eletivas e escolhas pragmáticas que são capazes de estabelecer categorias, que perduram ao longo da história nacional, aos intérpretes brasileiros em diferentes momentos do país (BRANDÃO, 2005).

Enxergando o pensar o pensamento como o exercício da ciência institucionalizada, a relevância de autores e pensadores utilizados para a análise contribui significativamente para os rumos da pesquisa em si, portanto determinar a influência direta dos intérpretes analisados tem o poder de categorizá-los como célebres ou marginais (BRANDÃO G. M., 2007). Compreender uma personalidade histórico-científica como célebre ou marginal, neste caso, envolve um processo de 
categorização subjetivo calcado quase que exclusivamente na noção abstrata de notoriedade do intelectual para o que é entendido como o fazer ciência política. Na apresentação de seu livro, Intérpretes do Brasil, Luiz Bernardo Pericás e Lincoln Secco (2014) utilizam como elemento de diferenciação entre o célebre e o marginal características como a não absorção pelo establishment acadêmico, o caráter outsider no emprego de algumas metodologias, as bases de análise dos pensadores e os modismos das influências teóricas de suas respectivas épocas. Como marginais, usualmente esquecidos ou menosprezados pelo fazer científico enquanto fonte de análise ou dados, eles caminharam ao longo da história ao lado dos célebres, comprovação da efetiva subjetividade da notoriedade vinculada à forma de classificação.

Na tentativa de exibir a complexidade por trás dessa classificação, bem como da importância do pensamento daqueles que ora foram vanguarda em ações e ideias, mas atualmente são esquecidos ou subestimados, este artigo procura recuperar, através de uma análise inicial, um dos nomes não consagrados para a ciência política, em especial o pensamento político brasileiro. Octávio Brandão, dirigente fundador do PCB em 1922, militante anarquista até 1921 e dirigente partidário afastado em 1928; teve atuações e papéis de destaque no que tange a incorporação do pensamento 'de esquerda' nas análises histórico, políticas, culturais e sociais brasileiras (PERICÁS \& SECCO, 2014). Entende-se, assim, como pensamento de 'esquerda' aqueles textos, discursos, palestras e outros materiais produzidos com posição antagônica ao liberalismo político, patrimonialismo e ao sistema econômico capitalista, mesmo que utilizado apenas na metodologia da análise dos sistemas políticos e econômicos do princípio do século XX no Brasil. Seguindo as linhagens do pensamento político, dentro das categorias de Gildo Marçal Brandão (2007), entende-se que Octávio Brandão, considerando a complexidade de sua trajetória, iniciada em 1917 com o lançamento do livro Canais e Lagoas, e sua autodenominação como "materialista científico", como precursor do "marxismo de matriz comunista" ${ }^{3}$. Ele prezava pela aplicação de uma análise dialética apreendida em

\footnotetext{
${ }^{3}$ Desde seus primeiros escritos a presente preocupação com o emprego de uma análise materialista e dialética, com a constante curiosidade sob o marxismo, que só conseguiu acessar em 1922, Octávio Brandão buscava trazer para as ciências naturais e humanas o rigor metodológico associado a uma leveza literária, uma expectativa de seguir os estudos e pensamento de Euclides da Cunha, cunhado no desenvolvimento dessa forma tipicamente dele de materialismo dialético (BRANDÃO, 1978).
} 
seus estudos solitários de filosofia clássica ao mesmo tempo que lera pensadores anarquistas, liberais e marxistas (BRANDÃO O. , Combates e Batalhas, 1978).

A escolha deste nome, para uma análise de caráter inicial, é calcada no papel histórico do pensador para o florescimento do pensamento de base marxista no país, seja no emprego da metodologia materialista histórico e dialético, seja na propositura de alternativas, história e críticas acerca da realidade e dos rumos do Brasil. Octávio Brandão, junto a Astrojildo Pereira, é considerado precursor da aplicação do marxismo na interpretação da trajetória brasileira. A práxis presente na sua militância política e o logos de sua atuação analítica como pensador das questões conjunturais nacionais, emprega o marxismo na formação das primeiras análises histórica baseadas no materialismo dialético enquanto tenta, no cotidiano, incorporar as diretrizes do marxismo revolucionário na vida política-econômica do país. Ele direciona, assim, um olhar sob o papel das formas econômicas para o desenvolvimento de um Brasil revolucionário (FAORO, 1987).

Enxergando Octávio Brandão, como inovador no uso de elementos do marxismo no pensamento político e social brasileiro, a análise que segue pretende demonstrar tanto a riqueza do seu pensamento marginal, em relação à sua época, quanto aliado às heranças deixadas por ele; sua contribuição no que cerne ao desenvolvimento das linhagens de pensamento genuinamente brasileiras. Essa colaboração para o debate sobre a existência de um pensamento originalmente brasileiro ou não, discussão que obrigatoriamente perpassa o pensar o pensamento, é um dos alicerces que contribuem para o desenvolvimento deste vasto campo de fronteira. Assim, pretende-se ao final deste artigo apresentar a importância de se considerar os pontos vistos como dissonantes nas estradas das interpretações sobre o país, sobretudo o marxista, e através dela colaborar com a discussão sobre a genuinidade dos frutos das mentes brasileiras ao longo da história do país, reforçando o argumento de que há um pensamento original na periferia do capitalismo no mundo. Como diria Schwarz (2014), um exercício de gravitação capaz de observar a relação entre a 'origem' no internacional e o resultado 'histórico', promulgado pelo constante pensar o pensamento em si, isto é, o fazer, refazer e analisar o pensamento político brasileiro na vida prática e nas análises teóricas. 


\section{O pensamento marginal}

A categorização subjetiva que divide intelectuais e demais pensadores sobre o Brasil, com base no impacto de suas ideias, como dito, descreve o relacionamento entre os meios institucionalizados das ciências humanas em geral para com estes personagens da história nacional. Cabe, neste momento, aprofundar sobre o que consiste de fato esse recurso metodológico, e a partir dele delimitar o porquê do autor escolhido esta categorizado como marginal.

Se a absorção do pensamento, teses e posturas dos pensadores que refletiram sobre o país está imbuída do desdobramento de notoriedade acadêmica; o questionamento inicial da razão classificatória é sobre o que é visto como científico ou não pela ciência política nacional. Partindo assim, da crítica de Florestan Fernandes (1980) sobre a produção de pensadores - no campo das ciências sociais - anteriores a ele, é possível começar uma classificação entre consagrado e marginal através do método de pesquisa empregado pelo intelectual analisado. Dessa forma, entendendo que o fazer ciência, necessita do emprego de métodos empíricos e teóricos, de referenciais metodológicos demarcados - seja positivista, crítico ou relativista, por exemplo - para assim defender suas teses e análises; o conceito de científico é delimitado a priori por estas prerrogativas. Isto significa que para as ciências humanas, em específico para as ciências sociais, o emprego de autores referenciáveis, análises de casos práticos e de descrição metodológica coerente com as influências teóricas se faz necessário para a escolha de autores como fontes capazes legitimar a pesquisa.

Não cabe a este artigo debater a relevância dos elementos categóricos que fazem dos autores inseríveis ou não no espaço e cotidiano acadêmico. No entanto, o que se pretende fazer é recuperar a razão desta classificação pré-formatada que se encerra no conhecimento e emprego dos autores em campos científicos capazes de absorvê-lo. Dirimindo possíveis consequências deste processo classificatório é possível compreender que, conforme lanni (1976) e Fernandes (1980) apresentam em suas análises sobre as ciências sociais feitas no país antes da institucionalização dela, os trabalhos feitos anteriormente a afirmação e legitimação destas ciências no país e em relação com a feita em outras regiões do mundo, foram classificados como ensaios 
sobre temas que passaram a ser melhor trabalhadas à partir dos cursos de graduação, mestrado e doutorado se firmarem no país. Porém a divisão entre o ensaísmo, os textos militantes, e as produções efetivamente acadêmicas não é o parâmetro principal do sistema classificatório mencionado neste artigo. A categorização entre célebre e marginal considera o uso de fatores mais subjetivos - absorção, leituras contemporâneas, entrada como referencial acadêmico, entre outros - do que a apresentação textual da produção feita pelo intelectual-objeto.

Portanto, mais do que a forma de apresentação das pesquisas e interpretações, a notoriedade de pensadores é associada também a trajetória de vida, por isso a relevância do aspecto subjetivo. A relevância do pensar o pensamento aplicada à formulação de categorias para viabilizar o processo de separação entre autores; não pelos seus textos, mas pelo aspecto relacional entre eles e suas trajetórias pessoais. Para compreender estes fatores mais abstratos e flexíveis, muitas vezes associados ao chamado modismo acadêmico, dois exemplos como Gilberto Freyre (1973) e Oliveira Viana (1999) são ilustrativos.

Freyre teve seu trabalho e obra fortemente influenciados por pensadores franceses e americanos, voltado para o exercício analítico com base em conceitos sociológicos e antropológicos do culturalismo, em seu livro mais famoso Casa Grande e Senzala (FREYRE, 1973), principalmente. Ele descreve, em um texto de fácil linguajar, a construção das relações étnico-raciais no país junto à formação e desenvolvimento das regiões brasileiras, com destaque para o nordeste. Já Oliveira Viana, parte, como em Instituições Políticas Brasileiras (VIANA, 1999), da análise sistemática sobre a estrutura e comportamento das instituições administrativas do país utilizando ferramentas metodológicas claras fundamentadas em filósofos e juristas italianos, franceses e americanos influentes no Brasil das décadas de 1910 a 1940.

Mesmo que ambos os trabalhos sejam do primeiro terço do século $X X$, a absorção atual dos autores é diferenciada. Enquanto Freyre (1973) fora marginal pelas ciências sociais pela falta de precisão e apaziguamentos cometidos em suas conclusões; Viana (1999) é uma espécie de coqueluche para a compreensão da formação do Estado brasileiro ao longo do século $\mathrm{XX}$, inclusive pelo peso de suas ideias nas ações governamentais até 1945. Os problemas do trabalho de Freyre (1973) sobrepujaram por muito tempo sua obra, levando-o a ser tratado como um ensaísta necessário apenas 
para conhecer a história da sociologia no país, uma espécie de referência do trabalho executado em um período da história das ciências sociais brasileiras. Por outro lado, com Viana (1999) o relacionamento é outro, suas controvérsias são relevadas em nome dos acertos e análises pertinentes que auxiliam atualmente a compreensão da relação do Estado com a sociedade civil; sob o papel das formas de autoritarismo, por exemplo.

Não significa que cada um dos autores citados não tenha importância para o exercício atual de novas análises e da construção de paradigmas sobre o país; o exemplo descreve a construção subjetiva e seletiva da notoriedade dos pensadores, personagens da história do pensamento político e social nacional, demonstrando a flexibilidade do conceito com base no referencial e resultado desejado. Na tentativa de superar essa barreira construída e constantemente remodelada, denominada nos corredores dos centros de produção acadêmica de 'modismo' ou tendência, que a busca pelos esquecidos se faz necessária.

Muito se debate sobre a existência ou não de um pensamento originalmente brasileiro. Se pretende, então, a partir de autores nativos determinar a que se refere este pensar o pensamento político brasileiro, colocando neste campo poroso da ciência o papel de ir além da multidisciplinaridade metodológica para buscar nos marginais novas fontes capazes de fortalecer a complexa formação do Brasil ao longo de sua história. Lembrando que ela é incessantemente construída pelos pensamentos e tendências intelectuais diversificadas, dotadas de características próprias (SCHWARZ, 2014). A revisão constante da categoria de celebridade e marginalidade se faz necessária, para que seja possível aliar os célebres e os marginais nas pesquisas, enriquecendo, assim, a compreensão do hoje e do amanhã a partir dessa miscelânea de perspectivas sobre a complexidade da política brasileira. A retomada de Octávio Brandão - o caso deste artigo - revisa a posição dele como intelectual, militante e pensador do Brasil, no campo do pensamento político, colocando-o no patamar de referencial analítico.

\section{Octávio Brandão: da militância radical no princípio do século XX}

Mesmo que marginal na classificação sistematizada até agora (PERICÁS \& SECCO, 2014), Brandão é um personagem da história política brasileira relevante quando o 
assunto é o marxismo no país. Alagoano, nascido na virada do século XIX para XX, sua trajetória política se inicia de forma difusa. Autodenominado de "materialista científico", ele percorre um caminho tortuoso até sua chegada no Rio de Janeiro, onde se assume, circunstancialmente, como anarquista

No Rio de Janeiro, em 1919-1921, procurei ansiosamente quem me informasse, com a devida exatidão, sobre as três perguntas: - Quem é Lênin? Que é marxismo? Que significa Revolução Russa? Não encontrei ninguém. As informações eram vagas, incertas, fragmentárias. Ninguém conhecia o marxismo. [...] Fui libertário, anarquista revolucionário em 1919-1921, durante dois anos e meio." (BRANDÃO O. ,Combates e Batalhas, 1978, p. $170)^{4}$

Essa posição radical sob o anarquismo pode ser compreendida pela forma como o pensador alagoano via tal proposta revolucionária. Adepto do cientificismo, com seus métodos e rigores das ciências naturais, formou-se em Farmácia em Recife (1912-1914), de onde migrou para a prática em sua cidade natal, Viçosa de Alagoas para, enfim, montar sua primeira farmácia em Maceió (1915-1919). Associava a vida de prático em enfermagem e farmácia com pesquisas em mineralogia, biologia, geologia, geografia física e política, escreve em 1917 seu primeiro livro Canais e Lagoas. A obra que o colocou numa posição política perigosa diante do olhar das elites nordestinas, dos trustes e seus agentes nacionais fazendo com que fosse obrigado a deixar sua 'amada' Alagoas em direção ao Rio de Janeiro. Era um estudante autodidata, pesquisador experimental, viajante e inconformado com a realidade política e social do Brasil, especialmente com o "abandono do povo brasileiro" (BRANDÃO O. , Combates e Batalhas, 1978).

A postura de aversão ao cristianismo ${ }^{5}$; o reconhecimento de fragilidade de sua situação econômica e social com os trabalhadores do campo, da cidade e miseráveis; o fascínio pela história do Quilombo de Palmares e Zumbi; e a admiração por Tiradentes, Castro Alves e Euclides da Cunha; numa realidade de formação escolar e condições de vida resultante dos cuidados - mesmo que sob ameaças - dos tios maternos, o colocou

\footnotetext{
${ }^{4}$ Grifos do autor.

${ }^{5}$ Atribuída por ele às perdas da mãe e do avô materno, aos 4 anos; do pai, aos 8 anos; e a separação precoce da irmã, com advento da morte da mãe (BRANDÃO, 1978).
} 
na vida política prática. A militância junto aos operários alagoanos, iniciada em 1917, o levou a discursar em piquetes, escrever manifestos, colunas de jornal e organizar reuniões. Conciliava, portanto a ambição das atividades de pesquisador das ciências naturais, o envolvimento político com os trabalhares, a vida de farmacêutico (atendia muitas vezes sem cobrar dos mais pobres) e suas aspirações literárias na poesia, filosofia, história e prosa.

Seu trânsito nessa diversidade de espaços culmina numa diversidade de obras; literatura naturalista aos moldes de Euclides de Cunha; poesia militante, segundo inspirações em Castro Alves; autobiografias; e obras analíticas sobre a estrutura geológica, ambiental, econômica, cultural e social do país, que aliavam sua prática militante com o "materialismo científico", que a partir de 1924 se tornou o viés marxista. Descrever este intelectual exige a lembrança do período em que ele fez e pensou a política do Brasil.

Como escritor manifesto, conheceu e se aliou a jornalistas, artistas e outros intelectuais, ainda em Maceió. Lá, seus textos de maior proeminência vieram das publicações no jornal Semana Social, a partir da amizade estabelecida com Antônio Bernardo Canellas ${ }^{6}$, jornalista, declaradamente anarquista, que mais tarde integraria o conjunto de militantes formadores do Partido Comunista do Brasil - PCB ${ }^{7}$. A publicação era repleta de críticas às posturas políticas do Estado brasileiro, em especial da província de Alagoas, e questões da conjuntura internacional. Posicionou-se contra a primeira Guerra Mundial. Sua postura crítica da terceira conferência proferida sobre o seu livro Canais e Lagoas, dos artigos de jornal e as atividades de militância colocaram Brandão como alvo de perseguições políticas constantes, policiais e oligárquicas.

Foram três conferências de divulgação da obra: a primeira e a segunda abordado questões técnicas como formação geológica, relevo, minerais e biomas, e a terceira abordou os problemas sociais, políticos e econômicos associados à miséria vista por ele ao percorrer todo o estado de Alagoas.

\footnotetext{
${ }^{6}$ Octávio Brandão (BRANDÃO, 1978) escreve o sobrenome do amigo com um "L" e Moraes, com 2. Optouse pela grafia de Moraes (MORAES e REIS FILHO, 2003).

7 Assim como sua amizade com o pintor João Moreira e Silva, sofreu perseguições da polícia pela proximidade com Canellas e seu jornal. A amizade com o artista lhe rendeu a primeira prisão, enquanto com o jornalista fez com que se escondesse na casa da irmã em Viçosa de Alagoas, e o amigo fechasse o jornal e deixasse Maceió para iniciar um novo periódico em Recife (BRANDÃO, 1978).
} 
Quais os objetivos das viagens e excursões? Escrever o livro Canais e Lagoas. Conhecer diretamente a Terra e o homem trabalhador. Pesquisar a natureza viva, o povo e a história. Descobrir as riquezas naturais em geral e indícios de petróleo em particular. Coligir matérias folclóricos. Investigar a formação e o desenvolvimento da terra, observar as condições de vida das populações. Conviver estreita e fraternalmente com os simples homens do povo pescadores, canoeiros, lavradores pobres. As condições de vida dos trabalhadores causaram-me um abalo profundo. Fiquei impressionado diante do contraste: a riqueza da terra e a miséria das populações. (BRANDÃO O. , Combates e Batalhas, 1978, p. 87)

A partir dele, como descreve a citação, as movimentações políticas de Brandão seguiram dois rumos que desagradavam as elites, locais, nacionais e as trustes: (a) começou uma mobilização em prol da defesa do petróleo nacional e da sua exploração nos territórios de Alagoas, Sergipe e Bahia; (b) trava um embate político e social em relação aos latifúndios e condições de trabalho no campo, passa a defender a reforma agrária e também o fim da forma de exploração definida por ele como resquício feudal (BRANDÃO O. , Combates e Batalhas, 1978). Assim, desagradando as elites, os riscos de prisão o forçaram a primeira experiência de clandestinidade e sua partida de Maceió rumo ao Rio de Janeiro em 1919.

Chegou ao Rio de Janeiro desempregado, contando apenas com alguns contatos como Astrojildo Pereira - com quem trocava correspondências - e outros colegas no campo da história, mineralogia, e outras ciências naturais. Almejou uma posição no Museu Nacional da qual desistiu após três tentativas fracassadas. Experimentou, ao longo de toda a vida, o convívio com a miséria eminente e o trabalho intermitente associados à solidariedade de companheiros de movimento, partido, familiares e a constante ajuda da companheira, Laura Brandão, com quem se casou em 1921. A participação nas atividades políticas dos trabalhadores da ferrovia, greves e publicações renderam 15 prisões entre 1919 e 1931. Além delas, apreensões em sua casa, e a desilusão com o movimento anarquista em 1921.

[...] quando chegou 1921, passei por uma crise. Dois anos e meio de anarquismo, eu vi que terminava em derrota. Caminho, não vejo nenhum. Ir para onde? Não tem. O ano de 1921 foi um ano de crise. Por um lado, uma felicidade extraordinária com Laura [...]; mas do outro lado, uma crise 
política moral e filosófica. Ir para onde? Não sei. Voltar ao anarquismo, não volto. $\mathrm{O}$ anarquismo está perdido. Foi o principal culpado dessas derrotas. Demos tudo. Sacrifício total [...]. Centenas de militantes e, no final, nada. E não víamos nenhuma saída. Por isso; porque o anarquismo não queria política, não queria a máquina do Estado; queria essas pequenas comunas agrícolas, o federalismo sem concentração. Então, não tinha futuro nenhum. Bakunin não compreendeu isso; Kropotkin não o compreendeu também; mesmo homens de valor como eles dois não compreenderam nada de nada. (BRANDÃO apud MORAES, 2014, p. 9)

Após as Grandes Greves de 1917 e 1919, havia acumulado mais derrotas do que vitórias, com, ainda, o retrocesso das conquistas destas Greves Gerais, do final dos anos 1910, o descumprimento dos acordos trabalhistas alcançados e as rupturas internas dos movimentos, Brandão rompe com a militância do anarco-sindicalismo carioca. Tendo como ponto culminante para sua dissidência a forma como foi recebida a Revolução Russa pelo movimento operário brasileiro, o pensador acreditava que era necessária uma nova formulação analítica sobre a realidade nacional. Era um defensor da Revolução de 1917, curioso pelo marxismo, especialmente pelo cientificismo por trás das informações que recebia sobre o trabalho de Marx, Engels e Lênin. Entendia que o momento histórico provocado pelo processo revolucionário russo, em 1917, consistia no fato destes revolucionários terem compreendido a realidade russa e através dos movimentos populares provocado o almejado rompimento com o imperialismo e o sistema capitalista em definitivo. Assim, Brandão assumiu uma postura comunista se distanciando do movimento operário brasileiro organizado sob as égides anarquistas.

Em 1921, se tornou militante do embrionário movimento do operariado comunista. Mais tarde, em 1922, aderiu ao recém-criado Partido Comunista do Brasil e teve como mentor seu antigo amigo de correspondências, Astrojildo Pereira, fundador do Partido. Eram colegas na militância operária. A proximidade entre eles permitiu que Pereira fosse o responsável pelos primeiros contatos entre Brandão e as obras de Lênin, Marx, Engels, Trotsky e Stálin. Como descreve Moraes (MORAES \& REIS FILHO, 2003), Brandão foi um dos precursores na tradução de obras clássicas do pensamento de Marx e do marxismo durante sua estadia no PCB; em 1923 traduziu para o português o Manifesto Comunista.

Sem abandonar as atividades práticas do movimento operário carioca, durante a primeira metade da década de 1920 Brandão dedicou-se ao estudo sistemático do 
comunismo, se debruçando sobre as escassas obras que chegavam ao país, as traduções francesas do $O$ Capital, alguns textos de Lênin, o resumo da obra $O$ Capital, de Marx e Engels, português escrito e publicado por Gabriel Deville em 1897. Foi partir de suas traduções e estudos particulares que Octávio Brandão escreve sua primeira análise sobre o Brasil, o livro Agrarismo e Industrialismo - Ensaio marxista-leninista sobre a revolta de São Paulo e a guerra de classes do Brasil, em 1924, publicado dois anos depois sob o pseudônimo Fritz Meyer em Buenos Aires. A repercussão da obra, na época, dentro do Diretório Central do PCB, levou o partido a atribuir diretrizes estratégicas divergentes da Internacional Comunista, como a participação das eleições de 1928, inclusive em sistemas de aliança. Estas diretrizes, posteriormente provocaram o afastamento da direção nacional pelo Diretório Latino-americano, tanto Astrojildo Pereira como Octávio Brandão foram expulsos dos postos de decisão partidária sobre o pretexto de alinhamento à pequena-burguesia do país.

Afastado do Comitê Central do PCB, em 1931, após o golpe de 1930, Brandão e outros militantes do Partido Comunista foram presos e posteriormente exilados. No exílio, Brandão instalou-se na União Soviética, onde permaneceu até o final da Segunda Guerra, em 1945. Durante sua estadia, estudou o socialismo, escreveu trabalhos literários, inclusive a conclusão de Combates e batalhas (BRANDÃO O. , Combates e Batalhas, 1978), obra de texto poético lírico, que segundo ele era 'inspirado pelo povo brasileiro'.

Instalado em Moscou, em 1937 organizou em Paris forte campanha pela libertação de Olga Benário e Anita Prestes, expatriada grávida pelo Estado Novo para o III Reich alemão. Apesar do sucesso na libertação da criança viu seus esforços minados pelo Comitê Central Brasileiro, em especial por Fernando Lacerda, representante e dirigente do PCB. Este episódio ilustra o fervor de Octávio Brandão presente simultaneamente nas suas atividades militantes práticas e teóricas.

\footnotetext{
"Passei três dias a ler recortes de jornais do brasil. Recolhi as últimas notícias. E tomei as iniciativas. [...] Tantos esforços de tantas organizações, personalidades e publicações, foram coroados de um triunfo magnífico. Em Berlim, a Gestapo teve de entregar Anita Prestes à avó. Vitória excepcional. [...] Fernando Lacerda continuava como "representante" do PCB. Esperava que eu fracassasse em Paris. Ficou com raiva e ainda mais hostil quando a luta foi coroada de vitória, com a libertação de Anita. Opôs-se
} 
categoricamente ao meu pedido relativo à Olga Benário. Alegou que se tratava de uma "provocação" de Brandão para agravar ainda mais as relações entre a União Soviética e a Alemanha nazista. Fernando fez tudo à socapa. Só vim a saber dessa trama dezessete anos depois, quando ele foi interrogado no Brasil pela direção do PCB. Ignorando a trama, insisti tenazmente no meu pedido à favor de Olga Benário. Nada consegui. Veio a agressão da Alemanha hitleriana à União Soviética, em 1941. A Gestapo aproveitou a guerra e matou Olga. Portanto, o "representante" do PCB, Fernando Lacerda, auxiliou de fato a Gestapo a assassinar Olga." (BRANDÃO apud MORAES, 2014, p. 13)

De volta ao Brasil, em 1946, retomou suas atividades políticas pelo PCB, elegendo-se vereador no Rio de Janeiro em 1947 e cassado logo em seguida pelo golpe judiciário no mesmo ano. Manteve sua militância política junto ao partido na clandestinidade, quando em 1958, voltou as atividades legalizadas. Com a denúncia dos crimes de Stálin, Brandão pouco a pouco se afastou da vida política, morrendo em 1980, aos 83 anos no Rio de Janeiro.

Conhecendo a trajetória e recepção do intelectual Octávio Brandão, para a história brasileira, em particular para a esquerda nacional; a análise da recepção de suas ideias fica mais clara. Como forma metodológica de sintetizar sua recepção como intelectual, a obra Agrarismo e Industrialismo (BRANDÃO O. , Agrarismo e Industrialismo, 2006), centralizará a observação sobre o ponto de vista dele, bem como sua recepção na época e contribuições que perduram até os dias atuais.

Apesar de controversa a importância da obra, o livro apresenta características inovadoras não somente sobre as leituras da realidade brasileira de sua época. A recepção, na época, dentro do PCB, foi positiva. A obra orientou estratégias - como foi dito - ao influenciar diretamente das decisões do próprio partido sobre o comportamento do movimento institucionalizado. Exemplo disso foi a formação do Bloco Operário Camponês (BOC) para as eleições de 1928. Na tentativa de compreender uma associação entre a proposta leninista e a realidade brasileira, descrita por ele em Agrarismo e Industrialismo, Brandão defende que é necessário superar o atraso retratado pelos 'resquícios feudais', a partir de uma associação entre os elementos sociais da modernidade presente no país: a burguesia, o operariado e o campesinato. Segundo ele, somente essa associação seria capaz de combater os dois grandes problemas do desenvolvimento nacional: o atraso agrário retratado pelas relações 
feudais nos latifúndios brasileiros, e a exploração do país pelo imperialismo europeu e estadunidense (BRANDÃO O. , Agrarismo e Industrialismo, 2006). A formação do BOC, em aliança com a burguesia nacional - para participação dos processos eleitorais resultaria, então nas condições necessárias para a modernidade trazida por uma 'revolução burguesa dentro da ordem', tirando o país do atraso e criando as condições para a revolução comunista.

Fora do partido, a obra foi objeto de estudo por parte da esquerda positivista da época, como os tenentistas. No entanto, com o passar do tempo, as deficiências da obra acabaram roubando a cena sob seus avanços. O próprio autor em um artigo intitulado Uma etapa da história de lutas, publicado em 1957, apresenta suas críticas ao livro se responsabilizando diretamente por posicionamentos considerados depois à direita, como a formação do BOC junto à esquerda positiva e aos pequeno-burgueses.

Esquecida após as duras críticas de meados do século XX, a obra de Brandão só voltou à tona através do exercício de pesquisas ligadas à História do marxismo e dos movimentos políticos brasileiros ao longo do século XX (MORAES \& REIS FILHO, 2003). Durante a década de 1990, diversos artigos incorporaram leituras discordantes sobre a obra em si, mas o consenso de sua importância histórica prevaleceu em sua maioria. Dentre estes estudos, estão das pesquisas de João Quartim de Moraes, Evaristo de Moraes Filho e Marcos Del Roio (MORAES \& REIS FILHO, 2003).

Partindo do emprego do trabalho e das ideias de Marx no Brasil, Evaristo Moraes Filho (MORAES \& REIS FILHO, 2003), em seu trabalho A Proto-história do marxismo no Brasil, apresenta o trabalho de Brandão como um livro marco de sua época no que tange a tentativa de desenvolver uma análise dialética-histórica do Brasil. No entanto destaca seus pontos negativos, demonstrando que segundo sua análise Agrarismo $e$ Industrialismo (BRANDÃO O. , Agrarismo e Industrialismo, 2006) teria sua importância reduzida ao marco histórico.

"O folheto não alcança as aspirações do autor. É um livro sectário, apaixonado, quase primário, que procura aplicar a dialética marxista à sociedade brasileira girando em torno da dicotomia centralizaçãodescentralização. [...] O início do livro, que lhe dá o título, é a luta entre o agrarismo e o industrialismo, aquele retrógrado e este moderno, representativos da luta entre ingleses e americanos pelo domínio da economia brasileira. Aplicada a dialética ao movimento de 1924: a tese é 
representada por Bernardes, agrarismo feudal; a antítese por Isidoro Dia Lopes, capital industrial infiltrado na pequena burguesia revoltada; finalmente, com a revolução proletária comunista, chegar-se-ia à síntese." (MORAES \& REIS FILHO, 2003, p. 49)

Já, Del Roio (MORAES \& REIS FILHO, 2003) apresenta em seu texto O impacto da Revolução Russa e da Internacional Comunista no Brasil, do mesmo ano e parte do mesmo livro historiográfico, o impacto na prática da obra, entendendo-a como deficitária e excludente sobre a questão camponesa. Mesma razão que segundo ele levaram às decisões do III Congresso Nacional do Partido Comunista, como a construção do BOC; e que no desenrolar dos acontecimentos, principalmente diante da crise política de 1930, resultaram na intervenção direta da Internacional Comunista - IC no partido brasileiro, provocando o afastamento de Brandão e outros dirigentes da direção do partido.

Por fim, numa análise mais profunda Moraes (2003) trata em específico do trabalho escrito por Brandão em A influência do leninismo de Stalin no comunismo brasileiro (MORAES \& REIS FILHO, 2003) bem como no texto denominado Octávio Brandão, que integra o livro Intérpretes do Brasil (PERICÁS \& SECCO, 2014). No primeiro trabalho o autor aproxima a leitura de Stálin com o livro Agrarismo e Industrialismo, apresentando diversas contribuições e acertos de Brandão sobre acontecimentos como a crise do café em 1929. A origem do termo marxismo-leninismo e o correto emprego do etapismo de Stálin, no que tange a determinação e conceptualização de termos como etapa, tática e estratégia, durante a análise das possibilidades de desenvolvimento e caminho para a revolução socialista. Para Moraes (2003) o termo marxismo-leninismo escrito por Brandão em 1927 precede o uso do mesmo nos trabalhos marxistas europeus, o mesmo vale para a distinção entre etapa, tática e estratégia feita em Agrarismo e Industrialismo e posteriormente, em 1928, por Stálin com as mesmas definições ao tratar sobre o processo revolucionário leninista e o processo que estabelece o Estado proletário, mais tarde denominado de stalinismo.

Diante destas recepções de seu trabalho, tal como o impacto de suas obras atualmente, é o momento de estabelecer as relações com a atualidade de seu pensamento. Seguindo o raciocínio de Moraes (2003), principalmente, tem-se na obra de Brandão a inauguração de perspectivas analíticas que vão para além da tentativa de 
emprego da dialética marxista diante da história nacional. Ao utilizar a divisão dos períodos brasileiros em ciclos associados ao perspectivismo do papel da população proletária no fazer revolucionário, seguindo os moldes do etapismo leninista; Octávio Brandão inaugura dentro da esquerda brasileira a tática, levada a cabo tanto sob o aspecto analítico quanto prático, da modernização à partir da revolução burguesa como momento obrigatório de antítese para o sucesso da síntese descrita como a revolução proletária. Além disso, o oposicionismo apresentado desde o título até os argumentos dialéticos, entre o rural e o urbano, retratam o pensamento que mais tarde será desenvolvido e debatido sobretudo quanto a problemática de desenvolvimento e subdesenvolvimento do país, chegando até os dias atuais na obra de Francisco de Oliveira, como O Ornitorrinco (OLIVEIRA, 2003). A capacidade analítica de Brandão, mesmo com deficiências de sua época, inaugura debates que perduram nas ciências humanas até os dias atuais dentro e fora da academia.

Estudos que compreendem o aspecto rural brasileiro como campesinatos ou trabalhos servis; que abordam uma ideia de etapas revolucionárias no país, como necessidades de superação do imperialismo em alinhamento com a burguesia nacional; são, em grande parte, resultante de derivações das interpretações de Octávio Brandão. Sua citação direta, não existe, como definido por ele mesmo

Dei tudo ao Brasil. Sacrifiquei a saúde e a liberdade. Arrisquei a vida muitas vezes. Mas não encontrei justiça nem compreensão. [...] Contribuí para dotar o Brasil com uma riqueza imensa - o petróleo. Mas não tenho trabalho, nem saúde, nem aposentadoria. Só aos 80 anos de idade é que consegui um "benefício" por velhice. Rende, por mês, apenas meio salário mínimo, 384 cruzeiros. E é tudo." (BRANDÃO O. , Combates e Batalhas, 1978, p. XXVI)

Por mais que ele mesmo não seja utilizado, por exemplo, como figurativo do etapismo apresentado no Programa do Partido Comunista Brasileiro em sua tese dos anos de 1940-1950, incluindo sua negligência para com o papel da questão agrária definindo os trabalhadores do campo como membros de formas de produção 'feudais' ou 'semi-feudais', seu afastamento da direção do partido no final da década de 1920 não significou a perda de importância de sua tese, base até hoje para análises de conjuntura por parte de movimentos e partidos de esquerda brasileiros. Se sua absorção pela comunidade acadêmica fica restrita a rememoração e reconstrução da história do 
pensamento marxista brasileiro, suas defesas analíticas não estão tão distantes das leituras de conjunturas brasileiras.

Exemplos disso, são trabalhos de pensadores atuais dentro da ciência política como Boito Junior em seu livro Política e Classes sociais no Brasil dos anos 2000 (BOITO JR. \& GALVÃO, 2012), no qual descreve claramente a necessidade da parceria operárioburguesa diante do apoio ao neodesenvolvimentismo como forma de derrotar o capitalismo imperialista industrial, como descreve o trecho abaixo.

\begin{abstract}
"A capacidade de pressão e, ao mesmo tempo, as limitações políticas do movimento operário e popular empurram, então, a grande burguesia interna para uma frente política que o próprio movimento operário e popular não tinha condições de dirigir. A frente está unificada, ainda que de maneira precária, em torno do neodesenvolvimentismo da grande burguesia interna, mas depende, para o seu sucesso, e em grande medida, do movimento operário e popular - que, no entanto, demonstra insatisfação com os limites desse projeto de desenvolvimento. Vale dizer, o movimento operário e popular não é a força hegemônica da frente, isto é, aquela que define os objetivos da luta, mas é a força principal, isto é, aquela de quem mais depende o sucesso da luta." (BOITO JR. \& GALVÃO, 2012, p. 72)
\end{abstract}

Demonstrando a necessidade da manutenção do papel da burguesia nacional associada às massas populares para a garantia de conquistas, como o embate e derrocada do capital internacional, Boito Junior (2012) não cita, mas emprega diretamente para o início do século XXI os principais elementos da análise feita por Brandão em Agrarismo e Industrialismo (BRANDÃO O. , Agrarismo e Industrialismo, 2006). O debate atual não se dispõe mais sobre a oposição campo indústria como no início do século XX, mas entre o capitalismo internacional e o desenvolvimento nacional como mote da história brasileira. Estas diferenças defendidas pelo autor contemporâneo, como proximidades às teses de 1950, na verdade como as teses citadas apresentam o reflexo e a reincorporação constante do pensamento de Brandão sobre o processo revolucionário comunista brasileiro. Se outrora fora condenado pela Internacional Comunista, como apresentou Del Roio (2003), hoje a tese apesar de debatida por vários autores ao longo de quase um século é ainda defendida em moldes que cabem a realidade atual. 
A contemporaneidade desse pensamento, bem como a forma de incorporação do marxismo-leninismo de Brandão pelos movimentos sociais nacionais, demonstra mais uma vez que por mais empoeirada que sua principal obra de caráter político esteja; sua capacidade de interlocução com a realidade política atual é sustentada pelo emprego de suas análises, mesmo que indiretamente, dentro da academia, por nomes renomados e por aqueles que permanecem na militância da esquerda brasileira como os movimentos urbanos, partidos comunistas e campesinos. Como Moraes (2003) descreve,

De poucas obras dir-se-á com razão serem tão paradoxais quanto Agrarismo e Industrialismo. Seus defeitos saltam aos olhos, mas não devem fazer perder de vista, além do pioneirismo doutrinário, a percepção, que nos parece justa, de que o principal conflito no Brasil de então opunha os interesses da nação aos das oligarquias agrárias. Também são globalmente justas suas observações sobre o imperialismo e a subordinação econômica dos interesses agrários à alta finança inglesa, bem como sobre as perspectivas sombrias que nos reservava nossa posição de monoexportadores de café. Quantos economistas e outros tagarelas neoliberais, do mercado, seriam capazes de previsões como a que o jovem intelectual comunista formulou no esconderijo a que o acuara a polícia de Artur Bernardes? (MORAES \& REIS FILHO, 2003, p. 161)

Diante das interpretações dos comentadores e da obra do autor a relevância do pensamento de Octávio Brandão parece incontestável. Mesmo que suas colocações não corroborem necessariamente para uma leitura efetivamente marxista ${ }^{8}$ sobre a história do Brasil, como entenderiam seus opositores no $\mathrm{PCB}$, o trabalho pioneiro de Brandão traz à luz uma técnica metodológica diferenciada para compreender as razões sobre a distância entre sociedade civil e Estado em um Brasil à beira de um dos mais icônicos golpes militares de sua história, em $1930^{9}$. É, portanto, uma questão de sincronia e diacronia de sua leitura conjuntural: se em 1928 propostas como o Bloco OperárioCamponês - BOC eram rechaçadas pela Internacional Comunista - IC, nos congressos posteriores as teses vencedoras - especialmente durante o período da Segunda Guerra Mundial - propunham alianças entre o campesinato, o operariado, a 'pequena-

\footnotetext{
${ }^{8}$ Entendendo que sua interpretação é, segundo Löwy, uma tentativa essencialista de emprego do marxismo na interpretação nacional (LÖWY, 1999).

${ }^{9}$ Considerando os trabalhos de Oliveira Vianna (VIANA, 1999), que guiaram doutrinas e diretrizes da política nacional após o golpe que colocou Getúlio Vargas na presidência do país por 15 anos consecutivos.
} 
burguesia' e muitas vezes a burguesia nacional. A disputa eleitoral era pauta relevante para os países centrais, semicoloniais e coloniais, nos Congressos da IC após 1930. Diretamente não se vê a propositura de Brandão, mas suas táticas e estratégias, descritas à partir de seus estudos das obras de Lênin e Trotsky, especialmente, foram parte da estratégia mundial da IC.

Portanto, falar de Octávio Brandão, no que tange à análise marxista é colocar um brasileiro nos cânones do desenvolvimento das teorias revolucionárias da primeira metade do século XX. Seu objetivo com Agrarismo e Industrialismo (BRANDÃO O. , Agrarismo e Industrialismo, 2006) não era esse, mas o desdobramento da profundidade de sua leitura torna essa ousadia possível. Quanto ao Brasil, objeto analítico do livro, suas interpretações orientaram historiadores do próprio PCB como Nelson Werneck Sodré, táticas como as de Luis Carlos Prestes, e dissidências inumeráveis. A interpretação sobre os ciclos econômicos e a relação antagônica entre país agrário e urbano será, a partir de Brandão, ponto e diálogo obrigatório dos agraristas e interpretes nacionais. Mesmo que o diálogo, novamente, não se dirija explicitamente ao trabalho do pensador alagoano, as suas teses desde então povoam as interpretações nacionais que tratam da complexidade do trabalho no campo, na cidade; da estrutura de classes nos dois espaços; e da forma como estes se relacionam (BRANDÃo O. , Agrarismo e Industrialismo, 2006). A dialética enxergada por ele entre cidade e campo, é ainda uma das posições de destaque nas interpretações da história política e social brasileira, com destaque para as pesquisas de Nelson Werneck Sodré (1990). Assim, ao falar de Brasil, intepretação histórica, econômica e material, obrigatoriamente a análise discute as teses desse autor marginalizado (RICÚPERO, 2000).

Revisando os marginais, como Brandão, cria-se a possibilidade de enxergar suas contribuições como originais de um pensamento político brasileiro. Mesmo cientes de que o debate clássico iniciando entre Santos (1967) e Lamounier (1976) restringe, parte da absorção, a reprodução ou reificação do pensamento liberal dentro do Brasil, é possível extrapolar a doutrina política liberal neste questionamento. É dentro da filosofia política e da própria teoria política que o pensamento comunista e marxista se fundamenta, focado no debate sobre o diagnóstico do emprego do liberalismo político e econômico, bem como de práticas alternativas. O uso das formas de apropriação do pensamento marxista no Brasil acaba por não fugir do célebre debate em si. 
Se por ventura hoje, intérpretes como Raymundo Faoro (1987), engajados no debate teórico sobre a análise do país ao mesmo tempo que esteve envolvido com a ação política em seu tempo; Octávio Brandão, dentro de seus estudos e militância, do anarquismo até o marxismo, não foge ao perfil de pensador. A tentativa de pensar o pensamento de Brandão, feita neste artigo, envolve o reconhecido deste não só como precursor e original no emprego da terminologia marxismo-leninismo na história do mundo, mas sim o reconhecimento de sua originalidade no uso metodológico da análise dialética histórica, como inovador na leitura da história econômica nacional - através do ciclos econômicos estabelecidos numa relação dialética entre o campo e a cidade (BRANDÃO O. , Agrarismo e Industrialismo, 2006), apresentando destaque ao papel dos ciclos econômicos no desenvolvimento do país - mais tarde "recapitulado" pela escola cepalina, como por Celso Furtado ${ }^{10}$. Aa dualidade tradicional e moderna, ilustrada pela queda de braço entre o poder latifundiário e do industrialismo nascente no início do século $X X$, que persistiu originando teorias sobre o conceito de subdesenvolvimento, modelos de crescimento e mais tarde a teoria da dependência como formas de compreender a relação entre a modernização e o conservadorismo na estrutura político social brasileira também podem ser creditadas inicialmente ao trabalho de Brandão.

Considerar original o pensamento de intérpretes dotados de instrumentos escassos como ele, é defender a capacidade descrita por Schwarz (2014) da contextualização do pensamento estrangeiro na difícil realidade do país colonizado em amplos aspectos; isto é, a absorção das ideias de origem estrangeira, no caso de Brandão, para a elaboração de teses de forma que o resultado é particular e privativo na análise da realidade nacional; pensamento autenticamente brasileiro no sentido estrito do termo.

\section{Bibliografia}

BOITO JR., A.; GALVÃO, A. (. ). Politicas e Classes Sociais no Brasil dos Anos 2000. São Paulo: Alameda, 2012.

\footnotetext{
${ }^{10}$ A leitura da modernização cepalina, em especial de Celso Furtado (2003), em que o tradicionalismo explicito no meio rural, enquanto relação social e forma de produção, advém da permanência dessa interpretação em que o capo brasileiro representa o atraso, e as cidades - especialmente as metrópoles do sudeste - representam a modernidade (BRANDÃO, 2006).
} 
BRANDÃO, G. M. Linhagens do Pensamento Político Brasileiro. DADOS - Revista de Ciências Sociais, v. 48, no 2, p. 231-269, 2005.

BRANDÃO, G. M. Linhagens do Pensamento Político Brasileiro. São Paulo: Hucitec, 2007.

BRANDÃO, O. Combates e Batalhas. São Paulo: Alfa-Omega, v. 1, 1978.

BRANDÃO, O. Agrarismo e Industrialismo. São Paulo: Editora Anita Garibaldi, 2006.

CEPEDA, V. Dilemas do Pensamento Político: Famílias intelectuais e as interpretações sobre o Brasil. In: BRANDÃO, G. M. Linhagens do Pensamento Político Brasileiro. São Paulo: Hucitec, 2007.

FAORO, R. Existe um Pensamento Brasileiro. Estudos avançados, vol.1, no1, p. 958, out/dez. 1987.

FAORO, R. Os Donos do Poder. São Paulo: Globo, 2012.

FERNANDES, F. A Revolução Burguesa no Brasil. Rio de Janeiro: Zahar, 1975.

FERNANDES, F. A sociologia no Brasil: Contribuição para o Estudo de sua Formação e Desenvolvimento. Petrópolis: Vozes, 1980.

FREYRE, G. Casa Grande e Senzala. Rio de Janeiro: José Olympio, 1973.

FURTADO, C. Formação Econômica do Brasil. São Paulo: Editora Nacional, 2003.

IANNI, O. Sociologia da Sociologia Latino-Americana. Rio de Janeiro: Civilização Brasileira, 1976.

LAMOUNIER, B. Formação de um Pensamento Político Autoritário na Primeira República - Uma Interpretação. Rio de Janeiro: Bertrand, 1976.

LE GOFF, J. História e Memória. Campinas: Unicamp, 2003.

LYNCH, C. Por que Pensamento e Não Teoria? A imaginação Político-Social Brasileira e o Fantasma da COndição Periférica. DADOS - Revista de Ciências Sociais, vol. 56, no 4, 2014. p. 727-767.

MORAES, J. Q.; REIS FILHO, D. A. (. ). História do Marxismo no Brasil. Campinas: Unicamp, v. I, II e IV, 2003.

OLIVEIRA, F. D. O Ornitorrinco - Crítica a Razão Dualista. São Paulo: Boitempo, 2003.

PERICÁS, L. B.; SECCO, L. (. ). Intérpretes do Brasil. São Paulo: Boitempo Editorial, 2014.

RICÚPERO, B. Caio Prado e a Nacionalização do Marxismo no Brasil. São Paulo: Editora 34, 2000.

RICUPERO, B. Sete Lições sobre a Interpretação do Brasil. São Paulo: Alameda, 2007.

SANTOS, W. G. Décadas de Espanto e uma Apologia Democrática. Rio de Janeiro: Rocco, 1967.

SCHWARZ, R. As Idéias fora do Lugar. São Paulo: Penguin, 2014.

SODRÉ, N. W. Formação Histórica do Brasil. Rio de Janeiro: Bertrand Brasil, 1990.

VIANA, O. Instituições Políticas Brasileiras. Brasília: Senado Federal, 1999. 